\title{
Accelerated Appearance of Multiple B Cell Lymphoma Types in NFS/N Mice Congenic for Ecotropic Murine Leukemia Viruses
}

\author{
Janet W. Hartley, Sisir K. Chattopadhyay, Marilyn R. Lander, \\ Lekidelu Taddesse-Heath, Zohreh Naghashfar, Herbert C. Morse III, and \\ Torgny N. Fredrickson
}

The Laboratory of Immunopathology (JWH, SKC, MRL, LT-H, ZN, HCM), National Institute of Allergy and Infectious Diseases; and The Registry of Experimental Cancers (TNF), National Cancer Institute, National Institutes of Health, Bethesda, Maryland

\begin{abstract}
SUMMARY: Spontaneous lymphomas occur at high frequency in NFS.V ${ }^{+}$mice, strains congenic for ecotropic murine leukemia virus (MuLV) proviral genes and expressing virus at high titer. In the present study, a total of $703 \mathrm{NFS}^{+} \mathrm{V}^{+}$lymphomas were studied by histopathology, immunophenotypic analysis, immunoglobulin heavy chain or T cell receptor $\beta$ chain rearrangements, and somatic ecotropic MuLV integrations; $90 \%$ of the lymphomas tested were of B cell lineage. Low-grade tumors included small lymphocytic, follicular, and splenic marginal zone lymphomas, while high-grade tumors comprised diffuse large-cell (centroblastic and immunoblastic types), splenic marginal zone, and lymphoblastic lymphomas. Comparison of mice of similar genetic background except for presence (NFS.V ${ }^{+}$) or absence (NFS.V ${ }^{-}$) of functional ecotropic MuLV genomes showed that NFS.V clonal lymphomas developed at about one-half the rate of those occurring in NFS. ${ }^{+}$mice, and most were low-grade B cell lymphomas with extended latent periods. In NFS.V ${ }^{+}$mice, clonal outgrowth, defined by lg gene rearrangements, was associated with acquisition of somatic ecotropic proviral integrations, suggesting that, although generation of $B$ cell clones can be virus independent, ecotropic virus may act to increase the rate of generation of clones and speed their evolution to lymphoma. The mechanism remains undefined, because only rare rearrangements were detected in several cellular loci previously associated with MuLV insertional mutagenesis. (Lab Invest 2000, 80:159-169).
\end{abstract}

$O$ ne of the earliest mammalian animal models in cancer research was the AKR mouse strain developed by Jacob Furth about 70 years ago. Selective breeding yielded mice with nearly $100 \%$ mortality due to thymic lymphoma in 7 to 14 months (Cole and Furth, 1941). AKR and the limited number of other $T$ cell lymphoma-prone mouse strains (C58, HRS, and some AKXD recombinant inbred (RI) lines) (Gilbert et al, 1993; Green et al, 1980; MacDowell and Richter, 1935; Meier et al, 1969; Mucenski et al, 1986, 1988) have been intensively studied, yielding a partial molecular understanding of the role of ecotropic and recombinant mink cell focus-inducing (MCF) murine leukemia viruses (MuLV) in pathogenesis of this earlyonset lymphoma (Cloyd et al, 1980; Hartley et al, 1977; Herr and Gilbert, 1983; Holland et al, 1985; ${ }^{\circ}$ Grath and Weissman, 1979; Rowe and Hartley, 1983; Stoye et al, 1991; Thomas et al, 1984). In contrast to those of $\mathrm{T}$ cell lineage, spontaneous $\mathrm{B}$ cell lymphomas are

Received August 25, 1999.

Supported in part by Contract NO1-AI-45203 at MA BioSystems, Inc., Rockville, Maryland.

Address reprint requests to: Dr. J. W. Hartley, LIP, NIAID, 7 Center Drive, Room 7/304, MSC-0760, National Institutes of Health, Bethesda, MD 20892-0760. Fax:301-402-0077; E-mail: jhartley@NIAID.NIH.gov. most commonly seen in aged mice of strains in which T cell lymphoma does not predominate. For example, the incidence of $B$ cell lymphoma of various types may be $30 \%$ or more in unmanipulated, aged BALB/c, C57BL (Frith and Wiley, 1981), AKR.Fv-1 ${ }^{\mathrm{b}}$ (HaranGhera et al, 1993), CWD (Angel and Bedigian, 1984; Mucenski et al, 1988; Thomas et al, 1989), or certain AKXD RI lines (Gilbert et al, 1993; Mucenski et al, 1986) held for up to 3 years, as well as in thymectomized AKR (Peled and Haran-Ghera, 1985) and $E_{\mu-}$ myc transgenic mice (Adams et al, 1985). In SL/Kh (Shimada et al, 1993; Yamada et al, 1994) and SJL/J (Haran-Ghera et al, 1967) mice, a high incidence of pre-B and lymphoplasmacytic B cell lymphomas, respectively, occurs earlier in life.

Previous studies of NFS.V congenic mice (NFS carrying the loci from AKR/N or C58/Lw that encode infectious ecotropic MuLV [Chattopadhyay et al, 1975; Rowe, 1978; Rowe and Kozak, 1980]) established that lymphomas occurred frequently (Fredrickson et al, 1984) and that the majority were nonthymic and of $B$ cell origin, as determined by analysis of expression of Ig and lineage-defining cell surface antigens (Fredrickson et al, 1985). Lymphomas developed within 200600 days, and high incidence was associated with high levels of ecotropic MuLV expressed early in life. NFS. $V^{+}$mice, represented by five strains descended 
from NFS.Akv1, NFS.Akv2, and NFS.C58v1, express high levels of ecotropic MuLV (NFS.V ${ }^{+}$). NFS. ${ }^{-}$ strains are genetically similar but lack ecotropic viral coding genes. The primary aims of studying this mouse population were (a) to examine the morphologic diversity of spontaneous B cell lymphomas, and (b) to study in detail the enhancing effect on B cell lymphomagenesis of expression of ecotropic MuLV, including examination for association with new somatic ecotropic proviral integrations, as has been reported for some myeloid leukemias in AKXD mice (Mucenski et al, 1987a, 1988) and for a few cases of B cell lymphoma, notably in CWD and SEA and certain AKXD mice (Gilbert et al, 1993; Justice et al, 1994; Mucenski et al, 1987a, 1988).

Over 700 hematopoietic neoplasms, $95 \%$ of which were lymphomas, occurring over a 5-year period in NFS.V ${ }^{+}$and NFS.V ${ }^{-}$strains were identified morphologically. Many were analyzed by Southern blot hybridization for identification of $\mathrm{T}$ or $\mathrm{B}$ lineage, clonal patterns, and new ecotropic proviral integrations. Lymphomas of B cell origin were 10-fold more frequent than T-lineage tumors, and all lymphomas tested comprised monoclonal or oligoclonal populations. New somatic integrations of ecotropic MuLV were found in $88 \%$ of NFS. $V^{+}$lymphomas tested, consistent with the reported close association of high titer of infectious ecotropic virus early in life with high lymphoma incidence (Fredrickson et al, 1984). Also, however, long-latency, low-grade lymphoma was detected in about $40 \%$ of mice without inducible ecotropic MuLV integrations, demonstrating that ecotropic MuLV expression is not an absolute requirement for initiation of lymphomagenesis but rather is important in accelerating progression.

\section{Results}

\section{Occurrence of Lymphomas in NFS. $V^{+}$Mice}

Mice were chosen for necropsy when they had developed enlarged lymph nodes and/or spleen, dyspnea due to enlargement of thymus or hilar nodes, or hind limb paralysis due either to compression of the spinal cord or to meningeal infiltration. In addition, some mice were selected for necropsy when spleens were determined by palpation to be about three times their normal size. Illness other than lymphoma was rare, but occasional mice succumbed to other hematopoietic neoplasms, epithelial tumors of the ovary, lung, mammary or adrenal gland, or Citrobacter freundii-induced colitis. Histopathologic diagnosis was based on published criteria (Fredrickson et al, 1995; 1999) conforming to those used for the Kiel Classification of human lymphomas (Lennert and Feller, 1992). Because REAL (Harris et al, 1994) and, more recently, the proposed WHO classifications (Jaffe et al, 1999) of human lymphomas are supplanting the Kiel system, we have proposed a "NIAID/NCI" classification of mouse lymphomas that parallels the WHO system in many respects (Morse et al, 1999; Taddesse-Heath and Morse, in press). The relations of this formulation to the Kiel-based system for the mouse (Fredrickson et al, 1995; Fredrickson and Harris, 1999) are presented in Table 1 as they pertain to diagnoses of lymphoma types occurring at greater than $1 \%$ frequency in our series.

The following considerations are important in understanding the new classification scheme. First, mouse $B$ cell lineage lymphomas with lymphoblastic morphology identical cytologically to human precursor lymphoblastic lymphoma (LL) include precursor B cell as well as surface immunoglobulin $\left(\mathrm{slg}^{+}\right)$lymphomas. Almost all cases of B lineage LL tested for Ig expression by immunocytochemistry or flow cytometry were positive, indicating that pre-BLL were not common in this series. At least some of the $\mathrm{slg}^{+} \mathrm{LL}$ comprise homologs of Burkitt-like lymphoma, but for the majority this is not yet established. Until the nature of the $\mathrm{slg}^{+}$"non-Burkitt" type is better understood, we will use the term B cell lymphoblastic lymphoma (B-LL) for all the $\mathrm{slg}^{+}$lymphomas with this morphology. Second, it has not been shown that mouse $\mathrm{T}$ cell lymphomas with lymphoblastic morphology are of the precursor type. We will refer to all $\mathrm{T}$ cell lymphomas with this morphology as $\mathrm{T}$ cell lymphoblastic lymphomas ( $\mathrm{T}$ LL). Third, splenic marginal zone lymphomas (MZL)

Table 1. Comparison of Classification Systems for Human and Mouse Lymphomas

\begin{tabular}{llll}
\hline & Proposed WHO (human) & $\begin{array}{c}\text { Proposed NIAID/NCI } \\
\text { (mouse) }\end{array}$ & Kiel-based (mouse) \\
\hline $\begin{array}{l}\text { Lymphomas of mature B cells } \\
\text { Low grade }\end{array}$ & $\begin{array}{l}\text { Small lymphocytic (SLL) } \\
\text { Follicular (FL) }\end{array}$ & SLL & SLL \\
& Marginal zone, splenic (MZL) & MZL & Centroblastic-Centrocytic (CBCCL) \\
Intermediate grade & Not defined & MZL + & MZL \\
High grade & Not defined & MZL + & MZL++ \\
& Diffuse large cell (DLCL) & DLCL & \\
& Centroblastic type (CB) & DLCL (CB) & Centroblastic follicular (CBLfol) \\
& Centroblastic diffuse (CBLdiff) \\
& Immunoblastic type (IB) & DLCL (IB) & Immunoblastic (IBL) \\
& Burkitt-like (BL) & DLCL (BL) & Lymphoblastic (B-LL) \\
\hline
\end{tabular}


have been shown to exhibit progression in grade (Fredrickson et al, 1999), and we indicate low-, intermediate-, and high-grade tumors of this type as $M Z L, M Z L+$, and MZL++. Finally, the Kiel definitions of lymphomas falling under the category of diffuse large cell (DLCL) in the WHO and NIAID/NCI systems have been termed immunoblastic (IBL), centroblastic follicular (CBLfol) to indicate probable origin from follicular cells and centroblastic diffuse (CBLdiff) to indicate tumors where the origin in the marginal zone or follicle could not be identified.

With these considerations in mind, the following provides a brief description of the histogenesis and morphology of lymphomas seen in NFS. ${ }^{+}$mice. Among the low-grade tumors, small lymphocytic lymphoma (SLL) initially is manifested as an increase in the small lymphocyte population of the splenic white pulp (Fig. 1A) with eventual spread into the red pulp and dissemination to lymph nodes, liver, lungs, and kidneys. Mitotic figures and large cells are rare, but leukemia is often seen. Follicular lymphomas (FL) form grossly discernible nodular growths that are seen mainly in the spleen and less frequently in lymph nodes. In these enlarged follicles, the normal population of small lymphocytes is displaced peripherally by one composed of centroblasts and centrocytes (Fig. 1B). Low-grade MZL presents as an increase in the normally sparse population of marginal zone cells (Fig. $1 \mathrm{C})$ to form distinctive perifollicular rings (Fredrickson et al, 1999). These rings increase in size and coalesce, filling the red pulp and fragmenting the follicles. Such progression to high grade is further manifested by accumulation of centroblasts and immunoblasts (Fig. 1D), often without changes in clonal populations (Fig. 1E).

High-grade lymphomas designated as DLCL(CB) (Fig. 1F) or DLCL(IB) (Fig. 1G) are of splenic origin but often spread to lymph nodes and extranodal sites, particularly the liver (Fig. 1G). Primary sites of LL involve lymph nodes for those of $B$ cell lineage or thymus in the case of T cell LL, with variable degrees of extension to the spleen. These are aggressive lymphomas with a characteristic growth pattern in which normal nodal structures are replaced with sheets of lymphoma cells that extend into surrounding adipose tissue, and there is frequent marked infiltration of liver, lungs, and kidneys. Cytologically, cells are generally of medium size, interspersed with numerous mitotic figures and variable numbers of tingible body macrophages engulfing apoptotic bodies (Fig. 1H).

Among 708 cases of hematopoietic neoplasms in NFS.Akv1, NFS.Akv2, and NFS.C58v1 mice, there were 677 lymphomas. Of these, 636 represented morphologic lymphoma types occurring at a frequency greater than 1\%, as shown in Table 2 for the five NFS.V ${ }^{+}$families combined. The relative frequency of lymphoma types was very similar for each family.

Lymphomas of the splenic marginal zone (MZL) were the most frequent, representing 38\% (240/636) when all morphologic grades (Fredrickson et al, 1999) were combined. MZL was largely limited to the spleen except for relatively minor involvement of splenic and mesenteric lymph nodes. The frequency of very large spleens (0.8 $\mathrm{g}$ or more) increased with progression in grade, being $5 \%$ for low-grade and $56 \%$ for highgrade MZL. Lymphoblastic lymphoma (LL) was next most frequently seen, at $27 \%$, and was diagnosed on average 3 months earlier than other lymphoma types. Early detection was facilitated by easily observed peripheral lymphadenopathy that was often more marked than splenomegaly even in B-LL. The remaining lymphoma types were about equally distributed, and the most consistent gross finding was splenomegaly. The frequency of $0.8 \mathrm{~g}$ or greater spleen weight was $65 \%$ for follicular lymphoma and ranged from $71 \%$ to $88 \%$ for DLCL of different morphologic subtypes. In low-grade SLL, only $39 \%$ of spleens reached this size. Overall, most mice not succumbing to $L L$ developed other types of lymphoma within 350 to 450 days; few mice survived beyond 600 days.

Although an accurate measure of overall incidence of lymphoma cannot be determined from these data because of periodic discards and early sacrifice, in an earlier study 52 NFS.V ${ }^{+}$mice were observed for diseases throughout their lifespan. Of these, 44 (85\%) developed terminal hematopoietic neoplasms, including lymphoma (36 cases), myeloid leukemia (4 cases), or histiocytic sarcoma. The frequency of lymphoma types was closely similar to that presented in Table 1 (data not shown).

\section{Molecular and Phenotypic Characterization of Lymphomas}

DNAs prepared from lymphoma tissue of 483 cases were analyzed by Southern blotting for rearrangements within immunoglobulin heavy chain $(\lg H)$ and $\mathrm{TCR} \beta$ genes in order to establish $\mathrm{B}$ or $\mathrm{T}$ cell lineages and to identify clonal populations (Table 3 ). In addition, 105 cases were examined by flow cytometry for cell surface antigen expression. In all DNAs, we detected clearly defined hybridization bands of random size and variable density, typically lighter in those samples with a high proportion of normal cells as judged by flow cytometry and/or histology. These bands were used to define clonal lymphoma populations as monoclonal, represented by one band or two of equal intensity, interpreted as indicating a rearrangement of one or both alleles; monoclonal/oligoclonal, represented by several bands of variable density but with a clearly predominant monoclonal population; and oligoclonal, typically three to five bands.

Ninety-two percent of all lymphomas tested, including $75 \%$ of the LL, demonstrated rearrangements of IgH but not TCR $\beta$ and were classed as B cell lymphomas. In 39 other DNAs, including $37 \mathrm{LL}$, clear clonal rearrangements, usually monoclonal, of the TCR $\beta$ locus established a T cell lineage. As shown in Table 3, in the majority of cases of each lymphoma type the rearrangements of $\mathrm{IgH}$ and $\mathrm{TCR} \beta$ were of monoclonal pattern (333/444 B cell and 36/39 T cell). Correlation of lineage determinations made by FACS analysis with those made by Southern blotting for rearrangements in immunoglobulin or T cell receptor genes was high. 

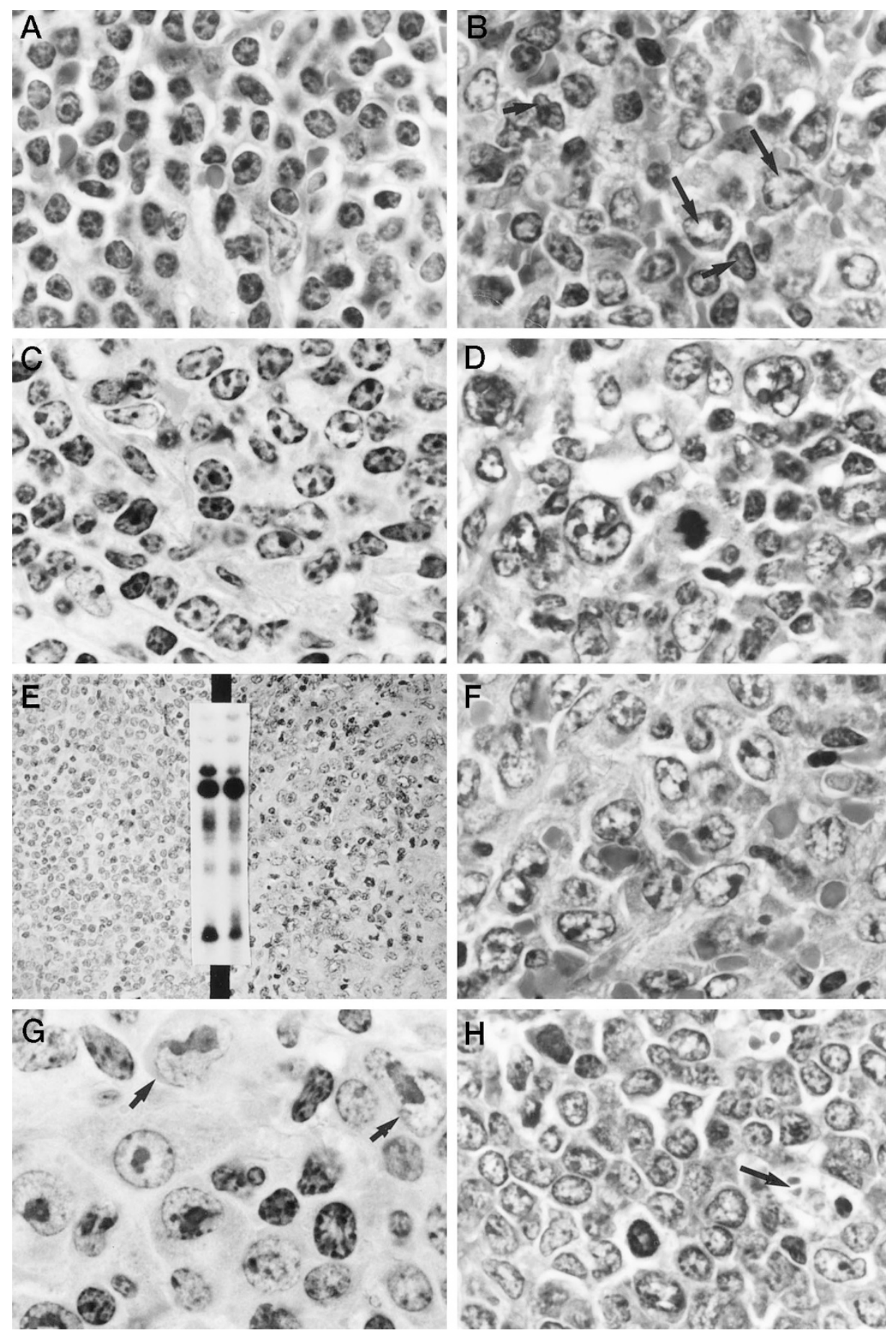

\section{Figure 1.}

$\mathrm{H} \& \mathrm{E} \times 300$ except as noted. $A$, SLL, showing mainly round nuclei containing one to several nucleoli; a rare mitotic figure is shown at upper center. $B$, FL, containing both centroblasts (arrows) and centrocytes with smaller darker nuclei (arrowheads). C, Low-grade MZL. Typical MZL cells form an expanded marginal zone and have round to ovoid nuclei separated by plentiful lightly staining cytoplasm. $D$, High-grade MZL ++ composed of a heterogeneous population dominated by large cells and featuring numerous mitotic figures (E) MZL as detected in spleen biopsy (left) and necropsy (right) samples, showing progression from low grade to high grade, respectively, with retention of the same clonal $J_{H}$ rearrangements (center pane). The interval from biopsy to necropsy was 40 days, with spleen weight increasing from approximately 300 to $600 \mathrm{mg}(\times 50)$. F, DLCL(CB) composed of large cells with round, vesicular nuclei containing two distinct nucleoli adhered to the nuclear membrane. (G) DLCL(IB), containing a high proportion of typical immunoblasts (arrows). H, LL, composed of fairly uniform, closely packed cells with ovoid nuclei, containing one to several nucleoli, interspersed with macrophages (arrow) containing apoptotic bodies.

Of cases that were analyzed by FACS and later found to have mono- to oligoclonal populations, 98 of 99 with $\mathrm{IgH}$ alterations were identified as $\mathrm{B}$ lineage lymphomas, while 6 of 6 with TCR $\beta$ rearrangements alone were $\mathrm{T}$ cell lymphomas. In about $70 \%$ of $\mathrm{T}$ cell lymphomas, rearrangements within the IgH locus were also detected, as observed previously (Fredrickson et al, 1993; Herr et al, 1983); the T cell lineage in a 
Table 2. Frequency of Different Morphologic Lymphoma Types in Lymphomas Occurring in NFS. $V^{+}$Mice

\begin{tabular}{lrcc}
\hline & $\begin{array}{c}\text { No. of } \\
\text { cases }\end{array}$ & $\begin{array}{c}\% \text { of lymphomas } \\
(\mathrm{n}=636)\end{array}$ & $\begin{array}{c}\text { Age at } \\
\text { diagnosis }\end{array}$ \\
\hline Low grade & & & \\
SLL & 57 & 9 & $408 \pm 101$ \\
FL & 37 & 6 & $436 \pm 111$ \\
MZL & 97 & 15 & $393 \pm 85$ \\
$\quad$ Subtotal & 191 & 30 & \\
Intermediate grade & & & \\
MZL+ & 54 & 8 & $425 \pm 88$ \\
High grade & & & \\
MZL++ & 89 & 14 & $407 \pm 84$ \\
DLCL & & & \\
$\quad$ CBLfol & 24 & 4 & $394 \pm 109$ \\
$\quad$ IBL & 38 & 6 & $396 \pm 126$ \\
$\quad$ CBLdiff & 58 & 9 & $394 \pm 89$ \\
LL & 182 & 27 & $282 \pm 112$ \\
$\quad$ Subtotal & 391 & 61 & \\
\hline
\end{tabular}

* Average age at diagnosis in days \pm standard deviation.

representative sample of these cases was confirmed by flow cytometric or immunocytochemical analysis.

\section{Ecotropic Viral Gene Analyses in Relation to B Cell Lymphomagenesis in NFS.V Congenic Mice}

Comparison of NFS. $V^{+}$and NFS. $V^{-}$strains. It was reported earlier (Fredrickson et al, 1984) that among NFS mice segregating for ecotropic MuLV sequences, lymphomas developed preferentially in those individuals expressing high titers of infectious ecotropic MuLV early in life, as compared with those with low titers or virus negative. In the course of the present study, it was noted that lymphomas occasionally were seen in a strain of similar genetic background but in which the ecotropic MuLV integration had been lost: NFS.c58v2eco-negative. Lymphoma was frequently detected only by histopathology, there being little or no splenomegaly. Overall, among 29 lymphomas seen during the 5-year period, there were 14 low-grade, 5 intermediate-grade, and 10 high-grade, with average latencies of $642 \pm 143$ days, $632 \pm 92$ days, and $364 \pm 195$ days.

Further evaluation of lymphomagenesis in virusnegative mice employed mice generated in the course of a recent re-derivation of one of the high-virus strains, NFS.Akv2 (4-2K). This strain presently carries three ecotropic MuLV integrations detectable in EcoRI digests: 25 kilobase $(\mathrm{kb})$, representing Emv12, the originally described Akv2 locus (Kozak and Rowe, 1980), and two additional bands of $22 \mathrm{~kb}$ and $15.3 \mathrm{~kb}$, respectively. $4-2 \mathrm{~K}$ mice were bred to the NFS.V ${ }^{-}$ stock and F2, backcross, and inbred progeny typed for presence of these bands and expression of ecotropic MuLV. The mice used in these matings were from inbred lines that had been backcrossed to NFS/N for 13 generations and could thus be considered as congenics. Groups were set aside for lifetime monitoring for lymphoma. Assays for infectious ecotropic virus (data not shown) revealed that the $25 \mathrm{~kb}$ band was consistently associated with expression of virus, detected by XC plaque assays of tail extract, splenic infectious centers or, in a minority of cases, by IUdR induction of tail cultures. Mice segregating for only the 22 kilobase $(\mathrm{kb})$ or $15.3 \mathrm{~kb}$ bands, as well as mice lacking a reactive band, were completely negative for infectious virus even upon IUdR treatment. Table 4

Table 3. Clonal Analysis of NFS. $V^{+}$Lymphomas: Southern Blot Hybridization to Detect Rearrangements of Immunoglobulin Heavy-Chain $(\mathrm{IgH})$ and T Cell Receptor $\beta$ Chain (TCR $\beta$ ) Genes

\begin{tabular}{|c|c|c|c|c|c|c|c|c|}
\hline \multirow[b]{3}{*}{ Lymphoma type* } & \multicolumn{8}{|c|}{ Clonal Patterns† } \\
\hline & \multicolumn{4}{|c|}{ IgH (No. with clonal pattern) } & \multicolumn{4}{|c|}{ TCR $\beta$ (No. with clonal pattern) } \\
\hline & No. cases & Mono & Mono/Oligo & Oligo & No. cases & Mono & Mono/Oligo & Oligo \\
\hline \multicolumn{9}{|l|}{ Low grade } \\
\hline SLL & 53 & $36(68)$ & $12(23)$ & $5(9)$ & 2 & $2(100)$ & 0 & 0 \\
\hline $\mathrm{FL}$ & 28 & $21(75)$ & $3(11)$ & $4(14)$ & 0 & & & \\
\hline MZL & 47 & $26(55)$ & $9(19)$ & $12(26)$ & 0 & & & \\
\hline \multicolumn{9}{|l|}{ Intermediate grade } \\
\hline MZL+ & 37 & $25(68)$ & $10(27)$ & $2(5)$ & 0 & & & \\
\hline \multicolumn{9}{|l|}{ High grade } \\
\hline MZL++ & 80 & $57(71)$ & $18(23)$ & $5(6)$ & 0 & & & \\
\hline \multicolumn{9}{|l|}{ DLCL } \\
\hline CBLfol & 17 & $14(82)$ & $0(0)$ & $3(18)$ & 0 & & & \\
\hline $\mathrm{IBL}$ & 33 & $22(67)$ & $6(18)$ & $5(15)$ & 0 & & & \\
\hline CBLdiff & 37 & $34(92)$ & $3(8)$ & $0(0)$ & 0 & & & \\
\hline $\mathrm{LL}$ & 112 & 98 (87) & $12(11)$ & $2(2)$ & 37 & $34(92)$ & $3(8)$ & 0 \\
\hline Total cases & 444 & $333(75)$ & 73 (16) & $38(9)$ & 39 & $36(92)$ & $3(8)$ & 0 \\
\hline
\end{tabular}


Table 4. Lymphoma Incidence and Frequency of Morphologic Types in NFS.Akv2 (4-2K) Populations Segregating for Germline Ecotropic MuLV Sequences

\begin{tabular}{|c|c|c|c|c|c|c|c|c|}
\hline \multirow[b]{3}{*}{ Lymphoma type $†$} & \multicolumn{8}{|c|}{ Ecotropic MuLV expression* } \\
\hline & \multicolumn{4}{|c|}{ Positive } & \multicolumn{4}{|c|}{ Negative } \\
\hline & No. & $\begin{array}{c}\% \text { of } \\
\text { lymphomas }\end{array}$ & Ageł & $\begin{array}{l}\text { Fraction } \\
\text { clonal§ }\end{array}$ & No. & $\begin{array}{c}\% \text { of } \\
\text { Iymphomas }\end{array}$ & Age & $\begin{array}{c}\text { Fraction } \\
\text { clonal }\end{array}$ \\
\hline \multicolumn{9}{|l|}{ Low grade } \\
\hline SLL & 8 & 12 & $570 \pm 106$ & $3 / 3$ & 3 & 12 & $706 \pm 19$ & \\
\hline $\mathrm{FL}$ & 11 & 16 & $570 \pm 74$ & $5 / 5$ & 1 & 4 & 658 & $1 / 1$ \\
\hline MZL & 24 & 36 & $526 \pm 118$ & $12 / 12$ & 16 & 64 & $612 \pm 104$ & $4 / 4$ \\
\hline Compositeी & 3 & 4 & $451 \pm 97$ & $1 / 1$ & 0 & & & \\
\hline Subtotal & 46 & 69 & & & 20 & 80 & & \\
\hline \multicolumn{9}{|l|}{ Intermediate grade } \\
\hline MZL+ & 0 & & & & 2 & 8 & 675 & \\
\hline \multicolumn{9}{|l|}{ High grade } \\
\hline MZL ++ & 2 & 3 & 553 & $1 / 1$ & 2 & 8 & 675 & \\
\hline $\mathrm{IBL}$ & 3 & 4 & $499 \pm 83$ & $1 / 1$ & 0 & & & \\
\hline CBLdiff & 3 & 4 & $551 \pm 14$ & $2 / 2$ & 0 & & & \\
\hline $\mathrm{LL}$ & 10 & 13 & $373 \pm 198$ & $6 / 6$ & 1 & 4 & 744 & $1 / 1$ \\
\hline Composite\# & 3 & 4 & $474 \pm 110$ & $2 / 2$ & 0 & & & \\
\hline Subtotal & 21 & 31 & & & 3 & 12 & & \\
\hline Total Iymphomas/no. of mice & $67 / 83$ & 81 & $511 \pm 132$ & $33 / 33$ & $25 / 61$ & 41 & $640 \pm 97$ & $6 / 6$ \\
\hline
\end{tabular}

* Ecotropic virus-positive mice carry the $25 \mathrm{~kb}$ germline EcoRI fragment hybridizing in Southern blotting with the EcoSp probe and associated with spontaneous and/or induced expression of infectious ecotropic MuLV. Mice in the virus-negative group carry EcoRI EcoSp-reactive fragments of $22 \mathrm{~kb}$, $15.3 \mathrm{~kb}$, or no reactive sequences.

† Abbreviations and definitions as for Table 1. Composite tumors are defined as two distinct lymphoma types occurring in the same spleen.

$\ddagger$ Age at diagnosis in days \pm standard deviation.

$\S$ Fraction clonal $=$ no. of cases with monoclonal or oligoclonal IgH or TCR $\beta$ rearrangements divided by no. tested.

ๆ Includes FL/MZL (3 cases).

\# Includes CBL/MZL (2), IBL/SLL (1).

presents the frequency of lymphoma types and the incidence after at least 18 months of observation. In virus-expressing mice carrying the $25 \mathrm{~kb}$ band alone or in combination with the $22 \mathrm{~kb}$ or $15.3 \mathrm{~kb}$ band, the incidence was 67 of $83(81 \%)$ with an average age at diagnosis of $511 \pm 132$ days, while for virus-negative segregants (pooled results of $22 \mathrm{~kb}, 15.3 \mathrm{~kb}$, and no band) the incidence was 25 of 61 (41\%) with a latency of $640 \pm 97$ days (chi square $=13.9 ; p=0.0002$ ). All lymphomas tested, whether in virus-positive or -negative mice, were monoclonal or oligoclonal.

Somatic provirus integration. As a basis for evaluating insertional mutagenesis by somatically acquired ecotropic MuLV proviral genomes, 181 NFS.V ${ }^{+}$B cell lymphomas representing all morphologic types were examined by Southern blot hybridization for new provirus integrations as determined by comparison with matching tail DNAs. Somatic integrations were detected in 162 lymphomas (90\%), and frequency was comparable in all morphologic types. The number of new integrations varied from one to six but was usually one or two. Bands were of variable hybridization intensity, many being quite faint. Examples of somatic and germline integrations are illustrated in Figure 2 for three lymphomas and one reactive spleen as compared with the respective tail samples. Three germline bands are seen in all samples; for 32472 and 32800 , there are one or two additional bands, indicative of reintegrations of proviruses in the germline. For the splenic lymphomas, but not the reactive spleen, there

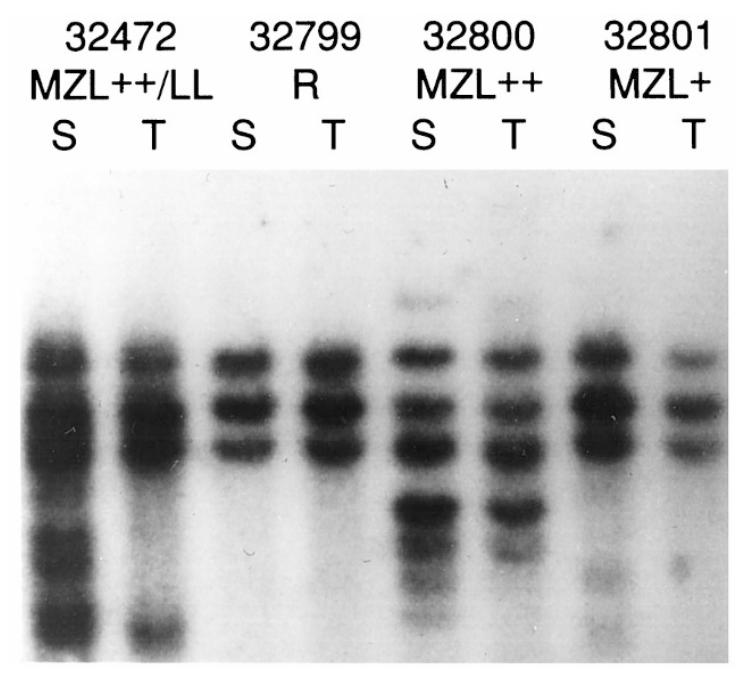

Figure 2.

Southern blot analyses for identification of somatic MuLV integrations in lymphomas of NFS. $\mathrm{V}^{+}$mice. DNA samples of spleens (S) and corresponding tail biopsies (T) from NFS.Akv2 mice were digested with EcoRI and hybridized with the ecotropic-specific probe EcoSp. Germline integrations are those also present in tail DNA. One to two somatic integrations are seen in the lymphoma DNAs, whereas the spleen with reactive $(R)$ changes had none.

are additional bands of variable intensity representing new somatic integrations.

Rearrangement of cellular genes. Probes representing several cellular genes identified in other lymphoma 
systems as activated or dysregulated by somatic MuLV integrations were used to screen DNA samples from B cell lymphomas for disruption of germline configurations of each oncogene. Forty to 80 examples of LL, SLL, MZL, FL, and each DLCL type were tested. Only rare rearrangements were detected in Myc (2/266) and Pim1 (4/100). All the rearrangements were found in LLs, except for Myc disruption in one DLCL(CB). It has not been determined whether these changes were occasioned by proviral insertion. No alterations were detected in Evi5, Fis1, or Ccnd1 (S. K. Chattopadhyay, X. Liao, and C.-F. Qi, unpublished data). Thus, these oncogenes are not frequent targets for insertional mutagenesis in NFS. $V^{+}$mice.

Pathogenicity of NFS. $V^{+}$Viruses. MuLV isolates from three B cell lineage NFS. $V^{+}$lymphomas, including one $\mathrm{LL}$, one SLL, and one high-grade MZL, were inoculated into newborn NIH Swiss or NFS/N mice. Only isolates from case 32458, the MZL, induced lymphoma; this mouse also had an osteosarcoma, but the significance of this is not known. Ten litters were inoculated with harvests of tissue culture passaged material containing both ecotropic and MCF viruses. Each litter yielded mice with lymphoma, the overall incidence being 30 of 61 (49\%) with an average latent period to disease of $347 \pm 125$ days. In the range of lymphoma types seen, LL predominated with 16 cases, $10 \mathrm{~B}$ cell and $6 \mathrm{~T}$ cell. Also found were six FL, five DLCL (two CBL and three IBL), two MZL, and one SLL. All of the 25 lymphoma DNAs tested contained one or more clonal integrations of ecotropic MuLV sequences. In contrast, 10 litters inoculated with MCF virus isolates alone yielded only five mice with lymphoma (5/60, 8\%; average latency $412 \pm 66$ days); there were four LL (one B cell and three T cell) and one FL. As would be expected, none of these lymphoma DNAs displayed ecotropic MuLV integrations.

Because pathogenic MCF viruses often require the presence of ecotropic virus for in vivo infection (Cloyd et al, 1981), five litters of NFS. ${ }^{+}$mice were inoculated with selected MCF-only harvests and observed for 7 months to test for acceleration of lymphoma development. Eight of 34 mice developed lymphoma (24\%), four LL (one B cell, three T cell), two MZL, and two SLL, with an average latency of $188 \pm 27$ days. Four of seven DNAs contained new somatic ecotropic virus integration. Although the average latency to tumor development differed markedly in the two groups of mice infected with MCF alone, the difference in incidence is not statistically significant (chi square $=2.7$; $p=0.1$ ). In the single litter inoculated with ecotropic MuLV alone, one tumor developed, an unusual splenic composite of myelogenous leukemia and histiocytic sarcoma. These data indicate that although lymphomas did develop in exogenously infected lowlymphoma mice, the complex representing pathogenic virus was not specific for a single lymphoma phenotype.

More efficient lymphoma induction observed with mixed ecotropic and MCF MuLV inocula could also suggest the presence of a replication-defective, pathogenic component. To examine this possibility, Hirt DNA was prepared from $M$. dunni cells infected with early $M$. dunni passage harvests of 32458 and examined by Southern blotting to determine the size of MuLV-reactive genomes. The DNA was digested with various restriction enzymes and hybridized with the EcoSp and MCFxenoSp probes. Only full-size genomes were detected. Although the ecotropic virus seems to be a pure population, there appear to be two or more components to the MCF virus population, one predominating (data not shown). Further analysis will be required to determine whether one or more have pathogenic potential.

\section{Discussion}

NFS. $V^{+}$mice, congenic for loci derived from the AKR and C58 strains that code for infectious ecotropic MuLV, develop a wide spectrum of B cell-lineage lymphomas, including several with striking similarities to human neoplasms. Lymphomas occur at high incidence, within about 8 to 18 months, and, in contrast to the T cell lymphomas of AKR and C58, the majority are of $B$ cell lineage. These include lymphoblastic, lymphocytic, and follicular types as well as MZL, only recently recognized as an important mouse lymphoma (Fredrickson et al, 1999; Ward et al, 1999; Yumoto et al, 1980). Although there is some variation in latency and frequency of individual lymphoma types, in three studies of hematopoietic neoplasms in NFS.V ${ }^{+}$mice carried out at intervals over the past 18 years, the lymphoma incidence in high-virus mice was $73 \%$ (Fredrickson et al, 1984), and $82 \%$ and $81 \%$ (this study) for mice observed at least 18 months.

The majority of lymphomas early in life were LL, $85 \%$ of cases occurring before 1 year of age, whereas MZL, SLL, FL, and DLCL lymphomas predominated in the second year of life. All of 483 NFS.V ${ }^{+}$lymphomas tested contained clonal populations defined by $\mathrm{lgH}$ or $\mathrm{TCR} \beta$ rearrangements, the majority being monoclonal.

Of the NFS.V ${ }^{+}$clonal B cell lymphomas tested, 90\% contained novel somatic ecotropic integrations, a frequency consistent with MuLV insertional mutagenesis as an important lymphomagenetic mechanism. In marked contrast to $\mathrm{T}$ cell lymphomas, targeting of cellular oncogenes (Mucenski et al, 1987b) or involvement of MCF MuLVs has been reported only infrequently for B lineage tumors (Armstrong et al, 1980; Gilbert et al, 1993; Mucenski et al, 1987b, 1988; Pals et al, 1986; Thomas et al, 1990; Zijlstra et al, 1983, 1986), but association of somatic ecotropic virus integrations in spontaneous pre-B or B cell lymphoma has been reported in certain AKXD RI strains (Gilbert et al, 1993; Justice et al, 1994; Mucenski et al, 1987a); CWD (Mucenski et al, 1988); SEA (Mucenski et al, 1988), C57BL (Zijlstra et al, 1986), SL/Kh (Yamada et al, 1994), and in graft-versus-host reaction in $\mathrm{CAF}_{1}$ mice (Pals et al, 1986).

The present study shows clearly, however, that mice of comparable genetic background to NFS.V ${ }^{+}$ but lacking sequences expressing infectious virus (NFS.V ${ }^{-}$mice) are not free of lymphoma. Such mice do develop clonal lymphomas, but at about one-half the frequency of those segregating for a virus 
induction-competent locus. Also, NFS.V ${ }^{-}$lymphomas were predominantly low grade and occurred with longer latency than NFS. ${ }^{+}$tumors (Table 4). T and B cell lymphomas also occur in p53-deficient mice, independent of any evidence of somatic integration of ecotropic proviruses (Ward et al, 1999) or expression of infectious virus (J. W. Hartley, unpublished data). The majority of $\mathrm{B}$ cell lesions involve premalignant hyperplasia of the marginal zone or relatively early stage MZL (Ward et al, 1999; L. Taddesse-Heath, unpublished data). We suggest, therefore, that a major influence of ecotropic MuLV on B cell splenic lymphomagenesis may be in hastening and intensifying an ongoing, presumably multistep process rather than its initiation. In virus-positive mouse strains, virus integration and spread also may play an important initiation role by stimulating the first emergence of clones at higher frequency. Mechanisms could include insertional mutagenesis and/or a direct or indirect effect of ecotropic or MCF MuLV-derived viral proteins. A mechanistically distinct role for MuLV in B cell lymphomagenesis could be through chronic low-level stimulation of the $B$ cell receptor, a possibility supported by the observations that NFS.V ${ }^{+}$lymphomas transplant to virus-positive but not to virus-negative mice (Fredrickson et al, 1985). Essentially all NFS.V ${ }^{+} \mathrm{B}$ cell lymphomas express CD5 (Fredrickson et al, 1999), and CD5 has been shown to interact with $\lg \mathrm{V}_{\mathrm{H}}$ framework sequences (Pospisil et al, 1996) as well as CD72 (Luo et al, 1992). Thus, signals provided by MuLV and CD5 could combine to promote B cell survival or proliferation, thus functioning as promoting factors in the evolution of the transformed state.

The demonstration of development of a variety of lymphomas following exogenous infection of very low lymphoma-incidence mice with uncloned mixtures of ecotropic and MCF MuLVs isolated from several B cell tumors is of potential importance. Although MCF viruses have been readily isolated from most NFS.V ${ }^{+}$ lymphomas tested, those characterized molecularly were of class II structure (Chattopadhyay et al, 1982; Lung et al, 1983) and were not oncogenic in AKR or NFS. ${ }^{+}$mice (Cloyd et al, 1980). It is noteworthy that studies using the Swiss mouse strain NMRI (Lovmand et al, 1998; Speth et al, 1995) uncovered a B lymphomagenic potential for Akv, the AKR-derived prototypic ecotropic MuLV strain, long considered nononcogenic, based on assays in other mouse strains. Other instances of B cell lymphoma induction by exogenous infection with either ecotropic or MCF MuLVs do not appear to be highly efficient (Thomas et al, 1990; Zijlstra et al, 1983; 1986). B cell lymphomas, mostly pre B-LL, can be induced by retroviruses that contain oncogenes such as $v$-abl (Abelson and Rabstein, 1970), v-cbl (Langdon et al, 1989), v-myc (Morse et al, 1986), or constructs of $v$-myc and $v$-raf (Kurie et al, 1990) or by infection of $E \mu-m y c$ transgenic mice with Moloney MuLV (Adams et al, 1985). In the case of pristane-induced plasmacytomas in BALB/c mice, the great majority of tumors carry translocations between c-Myc and the IgH locus (Potter and Wiener, 1992), but neither ecotropic nor MCF MuLV plays a role
(Potter et al, 1984). In spontaneous mouse lymphoma, association of any morphologic types with specific chromosomal translocations that result in structural changes in oncogenes has not been seen with any frequency or consistency. Recent studies, however, suggest a functional role for p53 in pathogenesis of MZL (Ward et al, 1999), for BCL6 in high-grade mouse $B$ cell lymphomas (C.F. Qi, et al. unpublished data, 2000), and possibly for cyclin D1 in low-grade lymphomas (Qi et al, 1998).

\section{Materials and Methods}

\section{Mice}

NFS.V congenic mice were bred and housed under conventional conditions at MA BioSystems, Inc. (Rockville, Maryland); both male and female mice were studied. These strains were established beginning in 1970 by Wallace Rowe, who developed several families of NFS/N mice bearing genes for independently segregating ecotropic proviruses of the high virusexpressing, high thymic lymphoma strains AKR/N and C58/Lw. Strain NFS/N lacks genetic information for ecotropic MuLV (Chattopadhyay et al, 1974) and has a very low incidence of lymphomas and other tumors (Fredrickson et al, 1984). Strains derived from AKR/N were initially bred to C57BR, then mated to NIH Swiss, backcrossed, and finally crossed to inbred NFS/N (Chattopadhyay et al, 1975; Rowe, 1978; Rowe and Kozak, 1980). C58/Lw was mated and backcrossed to NIH Swiss, then to NFS (Chattopadhyay et al, 1975; Fredrickson et al, 1985). Selection was by biological assay for high ecotropic virus expression, and segregation patterns in progeny tests were the basis for establishing families carrying single genes representing the parental provirus complement. Inbreeding of virus-positive segregants was begun at the N8 to N20 backcross to NFS. Since establishment of homozygosity, several inbred families have been maintained by brother-sister mating: five high-virus NFS. ${ }^{+}$families, including two NFS.Akv1 families carrying ecotropic MuLV locus Emv11 (Rowe et al, 1972); two families of NFS.Akv2, carrying Emv12 (Kozak and Rowe, 1980); and NFS.C58v1, carrying Emv26 (Kozak and Rowe, 1982). In addition to the originally described loci, ecotropic viral gene reinsertions have occurred (Rowe and Kozak, 1980; Buckler et al, 1982; S. K. Chattopadhyay, T. N. Fredrickson, H. C. Morse, III, and J. W. Hartley, unpublished data), and thus the number of germline integrations in each family is now generally increased and may vary among litter mates. Three sublines, each carrying a single provirus, were derived recently from one NFS.Akv2 family, 4-2K, which now carries three proviral integrations. These are designated $4-2 \mathrm{~K}(25 \mathrm{~kb}), 4-2 \mathrm{~K}(22 \mathrm{~kb})$, and $4-2 \mathrm{~K}(15.3 \mathrm{~kb})$ and are described further in Results. NFS. $V^{-}$mice derive from NFS.C58v2 (Fredrickson et al, 1984), a strain in which the original proviral integration was lost and that therefore carries no sequences hybridizing to the ecotropic MuLV-specific probe. 


\section{Tissue Sampling}

Spleen and occasionally lymph node and infiltrated nonlymphoid tissues, as indicated by gross findings, were routinely sampled for histopathology and frozen for later DNA extraction. In many cases, samples for flow cytometry and immunocytochemistry were also obtained.

\section{Histology}

Tissue samples were fixed in $10 \%$ buffered formalin for sectioning and staining with hematoxylin and eosin.

\section{Molecular Studies}

High molecular weight DNAs were prepared from lymphoid tissues or tail samples (Gross-Bellard et al, 1973) and analyzed by Southern blotting as previously described (Fredrickson et al, 1999). For immunoglobulin heavy chain $(\mathrm{IgH})$ rearrangements, DNAs were digested with EcoRI and hybridized with the J11 $\mathrm{J}_{\mathrm{H}}$ probe (Lang et al, 1982). To confirm similarity of hybridizing band size in paired DNAs from spleen biopsy and necropsy samples, Sacl and Xbal were used as required. For T cell receptor $\beta$ chain $(\mathrm{TCR} \beta)$ rearrangements, digestion was with Hpal and the probe was CT $\beta$ (Hedrick et al, 1985). To screen for somatic integrations of ecotropic MuLV, DNAs were digested with EcoRI and occasionally Pvull and probed with the ecotropic-specific probe EcoSp, a 400-bp Smal fragment (Chattopadhyay et al, 1980). For analysis of MCF MuLV genomes, an MCF-xenoSp probe (referred to as B-E in Chattopadhyay et al, 1982), which detects MCF and xenotropic MuLV sequences, was used.

\section{Flow Cytometry and Immunocytochemistry}

Single-cell suspensions prepared from splenic or lymph node lymphomas were stained with a panel of antibodies for two-color analyses using a FACScan (Becton Dickinson, San José, California) by established techniques using previously described antibodies (Fredrickson et al, 1999). Immunocytochemistry was performed on cryostat-sectioned frozen samples, as described previously (Fredrickson et al, 1999).

\section{Virus Assays and Mouse Inoculation}

Tests for expression of ecotropic MuLV used XC cell (ATCC CCL 165) plaque assays (Rowe et al, 1970) on SC-1 cells (ATCC CRL 1404) of tail extracts from 6- to 10-week-old mice or mitomycin C-treated spleen cell infectious centers (Cloyd et al, 1981). In some cases, virus expression was determined by induction of cultured tail cells with 5-iododeoxyuridine (Kozak and Rowe, 1982). Selected cell-free harvests of cocultivations of mitomycin C-treated lymphoma cells with SC-1 or M. dunni (Lander and Chattopadhyay, 1984) (ATCC CRL 2017) cells, tested for ecotropic virus by XC plaque assay or MCF MuLV by immunofluorescence with MCF-reactive monoclonal antibody 514
(ATCC CRL 1914), were inoculated $(0.04 \mathrm{ml}$, divided intraperitoneally and in the region of the thymus) into 1- to 3-day-old NFS/N or NIH Swiss mice obtained from the colonies of the National Institutes of Health.

\section{Acknowledgements}

The authors thank Dr. Karl Lennert (Kiel, Germany) for helpful consultation and discussions regarding lymphoma classification. We gratefully acknowledge the assistance of $\mathrm{N}$. Wolford and $\mathrm{E}$. Miller for help in storing and retrieving data. We also thank B. R. Marshall for skillful assistance in the preparation of the manuscript.

\section{References}

Abelson HT and Rabstein LS (1970). Lymphosarcoma: virusinduced thymic-independent disease in mice. Cancer Res 30:2213-2222.

Adams JM, Harris AW, Pinkert CA, Corcoran LM, Alexander WS, Cory S, Palmiter RD, and Brinster R (1985). The c-myc oncogene driven by immunoglobulin enhancers induces lymphoid malignancy in transgenic mice. Nature 318:533-538.

Angel JM and Bedigian HG (1984). Expression of murine leukemia viruses in B-cell lymphomas of $\mathrm{CWD} / \mathrm{Agl}$ mice. J Virol 52:691-694.

Armstrong MYK, Weininger RB, Binder D, Himsel CA, and Richards FF (1980). Role of endogenous murine leukemia virus in immunologically triggered lymphoreticular tumors. II. Isolation of B-tropic mink cell focus-inducing (MCF) murine leukemia virus. Virology 104:164-173.

Buckler CE, Staal SP, Rowe WP, and Martin MA (1982). Variation in the number of copies and in the genomic organization of ecotropic murine leukemia virus proviral sequences in sublines of AKR mice. J Virol 43:629-640.

Chattopadhyay SK, Cloyd MW, Linemeyer DL, Lander MR, Rands E, and Lowy DR (1982). Cellular origin and role of mink cell focus-forming viruses in murine thymic lymphomas. Nature 295:25-31.

Chattopadhyay SK, Lander MR, Rands E, and Lowy DR (1980). Structure of endogenous murine leukemia virus DNA in mouse genomes. Proc Natl Acad Sci USA 77:5774-5778.

Chattopadhyay SK, Lowy DR, Teich NM, Levine AS, and Rowe WP (1974). Evidence that the AKR murine leukemia virus genome is complete in DNA of the high-virus AKR mouse and incomplete in the DNA of the "virus-negative" NIH mouse. Proc Natl Acad Sci USA 71:167-171.

Chattopadhyay SK, Rowe WP, Teich NM, and Lowy DR (1975). Definitive evidence that the murine C-type virus inducing locus $A k v-1$ is viral genetic material. Proc Natl Acad Sci USA 72:906-910.

Cloyd MW, Hartley JW, and Rowe WP (1980). Lymphomagenicity of recombinant mink cell focus-inducing murine leukemia viruses. J Exp Med 151:542-552.

Cloyd MW, Hartley JW, and Rowe WP (1981). Genetic study of lymphoma induction by AKR mink cell focus-inducing virus in AKR $\times$ NFS crosses. J Exp Med 154:450-458.

Cole RK and Furth J (1941). Experimental studies on the genetics of spontaneous leukemia in mice. Cancer Res 1:957-965. 
Fredrickson TN and Harris AW (1999). Atlas of mouse hematopathology. Sydney: Harwood Academic Publishers [in press].

Fredrickson TN, Hartley JW, and Morse HC III (1993). Early divergence of erythroid lineage suggested by gene rearrangements in mouse hematopoietic neoplasms. Exp Hematol 21:354-357.

Fredrickson TN, Hartley JW, Morse HC III, Chattopadhyay SK, and Lennert K (1995). Classification of mouse lymphomas. Curr Top Microbiol Immunol 194:109-116.

Fredrickson TN, Lennert K, Chattopadhyay SK, Morse HC III, and Hartley JW (1999). Splenic marginal zone lymphomas of mice. Am J Pathol 154:805-812.

Fredrickson TN, Morse HC III, and Rowe WP (1984). Spontaneous tumors of NFS mice congenic for ecotropic murine leukemia virus induction loci. J Natl Cancer Inst 73:521-524.

Fredrickson TN, Morse HC III, Yetter RA, Rowe WP, Hartley JW, and Pattengale PK (1985). Multiparameter analyses of spontaneous nonthymic lymphomas occurring in NFS/N mice congenic for ecotropic murine leukemia viruses. Am J Pathol 121:349-360.

Frith CG and Wiley LD (1981). Morphologic classification and correlation of incidence of hyperplastic and neoplastic hematopoietic lesions in mice with age. J Gerontol 36:534-545.

Gilbert DJ, Neumann PE, Taylor BA, Jenkins NA, and Copeland NG (1993). Susceptibility of AKXD recombinant inbred mouse strains to lymphomas. J Virol 67:2083-2090.

Green N, Hiroshi H, Elder JH, Schwartz RS, Khiroya RH, Thomas CY, Tsichlis PN, and Coffin JM (1980). Expression of leukemogenic recombinant virus associated with a recessive gene in HRS/J mice. J Exp Med 152:249-264.

Gross-Bellard M, Oudet P, and Chambon P (1973). Isolation of high molecular weight DNA from mammalian cells. Eur J Biochem 36:32-37.

Haran-Ghera N, Kotler M, and Meshorer A (1967). Studies on leukemia development in the SJL/J strain of mice. J Natl Cancer Inst 39:653-661.

Haran-Ghera N, Peled A, Brightman BK, and Fan H (1993). Lymphomagenesis in AKR.Fv- $1^{\mathrm{b}}$ congenic mice. Cancer Res 53:3433-3438.

Harris NL, Jaffe ES, Stein H, Banks PM, Chan JKC, Cleary ML, Delsol G, deWolf-Peeters C, Falini B, Gatter KC, Grogan TM, Isaacson PG, Knowles DM, Mason DY, Muller-Hermelink H-K, Pileri SA, Piris MA, Ralfkiaer E, and Warnke RA (1994). $A$ revised European-American classification of lymphoid neoplasms: A proposal from the International Lymphoma Study Group. Blood 84:1361-1392.

Hartley JW, Wolford NK, Old LJ, and Rowe WP (1977). A new class of murine leukemia virus associated with development of spontaneous lymphomas. Proc Natl Acad Sci USA 74: 789-792.

Hedrick SM, Germain RN, Bevan MJ, Dorf M, Engel I, Fink P, Gascoigne N, Heber-Katz E, Kapp J, Kaufmann Y, Kaye J, Melchers F, Pierce C, Schwartz R, Sorensen C, Taniguchi M, and Davis MM (1985). Rearrangement and transcription of a T-cell receptor $\beta$-chain gene in different T cell subsets. Proc Natl Acad Sci USA 82:531-535.

Herr W and Gilbert W (1983). Somatically acquired recombinant murine leukemia proviruses in thymic leukemias of AKR/J mice. J Virol 46:70-82.
Herr W, Perlmutter AP, and Gilbert W (1983). Monoclonal $A K R / J$ thymic leukemias contain multiple $J_{H}$ immunoglobulin gene rearrangements. Proc Natl Acad Sci USA 80:74337436 .

Holland CA, Hartley JW, Rowe WP, and Hopkins N (1985). At least four viral genes contribute to the leukemogenicity of murine retrovirus MCF 247 in AKR mice. J Virol 53:158-165.

Jaffe ES, Harris NL, Diebold J, and Muller-Hermelink H-K (1999). World Health Organization classification of neoplastic diseases of the hematopoietic and lymphoid tissues. A progress report. Am J Clin Pathol 111:S8-S12.

Justice M, Morse HC III, Jenkins NA, and Copeland NG (1994). Identification of Evi-3, a novel common insertion site of retroviral integration in mouse AKXD B-cell lymphomas. J Virol 68:1293-1300.

Kozak CA and Rowe WP (1980). Genetic mapping of the ecotropic virus-inducing locus $A k v-2$ of the AKR mouse. J Exp Med 152:1419-1423.

Kozak CA and Rowe WP (1982). Genetic mapping of ecotropic murine leukemia virus-inducing loci in six inbred strains. J Exp Med 155:524-534.

Kurie JM, Morse HC III, Principato MA, Wax JS, Troppmair J, Rapp UR, Potter M, and Mushinski JF (1990). v-myc and v-raf act synergistically to induce B-cell tumors in pristane-primed adult BALB/c mice. Oncogene 5:577-582.

Lander MR and Chattopadhyay SK (1984). A Mus dunni cell line that lacks sequences closely related to endogenous murine leukemia viruses and can be infected by ecotropic, amphotropic, xenotropic, and mink cell focus-forming viruses. J Virol 52:695-698.

Lang RB, Stanton LW, and Marcu KB (1982). On immunoglobulin heavy chain switching: Two $\gamma 2 \mathrm{~b}$ genes are rearranged via switch sequences in MPC-11 cells but only one is expressed. Nucl Acids Res 10:611-630.

Langdon WY, Hartley JW, Klinken SP, Ruscetti SK, and Morse HCIII (1989). v-cbl, an oncogene from a dual recombinant murine retrovirus that induces early $B$-lineage lymphomas. Proc Natl Acad Sci USA 86:1168-1172.

Lennert K and Feller A (1992). Histopathology of nonHodgkin's lymphomas, 2 nd edition. New York: SpringerVerlag.

Lovmand J, Sørensen AB, Schmidt J, Østergaard M, Luz A, and Pedersen FS (1998). B cell lymphoma induction by Akv murine leukemia viruses harboring one or both copies of the tandem repeat in the U3 enhancer. J Virol 72:5745-5756.

Lung ML, Hartley JW, Rowe WP, and Hopkins NH (1983). Large RNase T1-resistant oligonucleotides encoding p15E and the $\mathrm{U} 3$ region of the long terminal repeat distinguish two biological classes of mink cell focus-forming type $\mathrm{C}$ viruses of inbred mice. J Virol 45:275-290.

Luo W, van de Velde $\mathrm{H}$, von Hoegen I, Parnes JR, and Thielemans K (1992). Ly-1 (CD5), a membrane glycoprotein of mouse $T$ lymphocytes and a subset of $B$ cells, is a natural ligand of the B cell surface protein Lyb-2 (CD72). $\mathrm{J}$ Immunol 148:1630-1634.

MacDowell EC and Richter MN (1935). Mouse leukemia. IX. The role of heredity in spontaneous cases. Arch Pathol 20:709-724 
McGrath MS and Weissman IL (1979). AKR leukemogenesis: Identification and biological significance of thymic lymphoma receptors for AKR retroviruses. Cell 17:65-75.

Meier H, Meyers DD, and Huebner RJ (1969). Genetic control by the $h r$-locus of susceptibility and resistance to leukemia. Proc Natl Acad Sci USA 63:759-763.

Morse HC III, Hartley JW, Fredrickson TN, Yetter RA, Majumdar C, Cleveland JL, and Rapp UR (1986). Recombinant murine retroviruses containing avian $\mathrm{v}-m y c$ induce a wide spectrum of neoplasms in newborn mice. Proc Natl Acad Sci USA 83:6868-6872.

Morse HC III, Qi C-F, Taddesse-Heath L, Chattopadhyay SK, Ward JM, Coleman A, Hartley JW, and Fredrickson TN (1999). Novel aspects of murine B cell lymphomas. Curr Topics Microbiol Immunol 246:249-254.

Mucenski ML, Bedigian HG, Shull MM, Copeland NG, and Jenkins NA (1988). Comparative molecular genetic analysis of lymphomas from six inbred mouse strains. J Virol 62:839846.

Mucenski ML, Gilbert DJ, Taylor BA, Jenkins NA, and Copeland NG (1987b). Common sites of viral integration in lymphomas arising in AKXD recombinant inbred mouse strains. Oncogene Res 2:33-48.

Mucenski ML, Taylor BA, Copeland NG, and Jenkins NA (1987a). Characterization of somatically acquired ecotropic and mink cell focus-forming viruses in lymphomas of AKXD recombinant inbred mice. J Virol 61:2929-2933.

Mucenski ML, Taylor BA, Jenkins NA, and Copeland NG (1986). AKXD recombinant inbred strains: Models for studying the molecular basis of murine lymphomas. Mol Cell Biol 6:4236-4243.

Pals ST, Zijlstra M, Radaszkiewicz T, Quint W, Cuypers HT, Schoenmakers HJ, Melief CJM, Berns A, and Gleichmann E (1986). Immunologic induction of malignant lymphoma: Graft-vs-host reaction-induced B cell lymphomas contain integrations of predominantly ecotropic murine leukemia proviruses. J Immunol 136:331-339.

Peled A, and Haran-Ghera N (1985). A high incidence of B cell lymphoma derived from thymectomized AKR mice expressing TL.4 antigen. J Exp Med 162:1081-1086.

Pospisil R, Fitts MG, and Mage RG (1996). CD5 is a potential selecting ligand for $B$ cell surface immunoglobulin framework region sequences. J Exp Med 184:1279-1284.

Potter M, Hartley JW, Wax JS, and Gallahan D (1984). Effect of MuLV-related genes on plasmacytomagenesis in BALB/C mice. J Exp Med 160:435-440.

Potter M and Wiener F (1992). Plasmacytomagenesis in mice: Model of neoplastic development dependent upon chromosomal translocations. Carcinogenesis 13:1681-1697.

Qi C-F, Chattopadhyay SK, Lander M, Kim Y, Fredrickson TN, Hartley NW, and Morse HC III (1998). Expression of cyclin D1 in mouse B cell lymphomas of different histologic types and differentiation stages. Leuk Res 22:395-404.

Qi C-F, Hori M, Coleman AE, Torrey TA, Taddesse-Heath L, Ye BH, Chattopadhyay SK, Hartley JW, and Morse HC III (In Press, 2000). Genomic organization and expression of BCL6 in marine B-cell lymphoma. Leuk Res.

Rowe WP (1978). Leukemia virus genomes in the chromosomal DNA of the mouse. In: Zabriskie JB, editor. Harvey Lectures, Series 71. New York: Academic Press, 173-192.
Rowe WP and Hartley JW (1983). Genes affecting mink cell focus-inducing (MCF) murine leukemia virus infection and spontaneous lymphoma in AKR F1 hybrids. J Exp Med 158:353-364.

Rowe WP, Hartley JW, and Bremner T (1972). Genetic mapping of a murine leukemia virus-inducing locus of AKR mice. Science 178:860-862.

Rowe WP and Kozak CA (1980). Germ-line reinsertions of AKR murine leukemia virus genomes in $A k v-1$ congenic mice. Proc Natl Acad Sci USA 77:4871-4874.

Rowe WP, Pugh WE, and Hartley JW (1970). Plaque assay techniques for murine leukemia viruses. Virology 42:11361139.

Shimada MO, Yamada Y, Nakakuki Y, Okamoto K, Fukumoto M, Honjo T, and Hiai H (1993). SL/KH strain of mice: A mode of spontaneous pre-B-lymphomas. Leuk Res 17:573-578.

Speth C, Luz A, Strauss PG, Wendel S, Zeidler R, Dorn S, Erfle V, Brem G, Lipp M, and Schmidt J (1995). Akv murine leukemia virus enhances lymphomagenesis in myc- $\kappa$ transgenic and in wild-type mice. Virology 206:93-99.

Stoye JP, Moroni C, and Coffin JM (1991). Virological events leading to spontaneous AKR thymomas. J Virol 65:12731285.

Taddesse-Heath L, and Morse HC III (2000). Lymphoma in genetically engineered mice. In: Ward JM, Mahler J, Maronpot RR, Sundberg JP, and Frederickson R, editors. Pathology of genetically engineered mice. Ames, lowa: lowa State University Press [in press].

Thomas CY, Buxton VK, Roberts JS, Boykin BJ, and Innes D (1989). Phenotypic heterogeneity of spontaneous lymphomas of CWD mice. Blood 73:240-247.

Thomas CY, Coppola MA, Holland CA, and Massey AC (1990). Oncogenicity and U3 regions sequences of class II recombinant MuLVs of CWD mice. Virology 176:166-177.

Thomas CY, Khiroya R, Schwartz RS, and Coffin JM (1984). Role of recombinant ecotropic and polytropic viruses in the development of spontaneous thymic lymphomas in HRS/J mice. J Virol 50:397-407.

Ward JM, Taddesse-Heath L, Perkins SN, Chattopadhyay SK, Hursting SD, and Morse HCIII (1999). Splenic marginal zone B cell and thymic T cell lymphomas in p53-deficient mice. Lab Invest 79:3-14.

Yamada Y, Matsushiro H, Ogawa MS, Okamoto K, Nakakuki Y, Tokokuni S, Fukumoto M, and Hiai H (1994). Genetic predisposition to pre-B lymphomas in SL/Kh strain mice. Cancer Res 54:403-407.

Yumoto T, Yoshida Y, Yoshida H, Ando K, and Matsui K (1980). Prelymphomatous and lymphomatous changes in splenomegaly of New Zealand Black mice. Acta Pathol Jpn 30:171-186.

Zijlstra M, deGoede REY, Schoenmakers HJ, Schinkel AH, Hesselink WG, Portis JL, and Melief CJM (1983). Naturally occurring leukemia viruses in $\mathrm{H}-2$ congenic C57BL mice. III. Characterization of C-type viruses isolated from lymphomas induced by milk transmission of B-ecotropic virus. Virology 125:47-63.

Zijlstra M, Quint W, Cuypers T, Radaszkiewicz T, Schoenmakers $H$, deGoede R, and Melief C (1986). Ecotropic and mink cell focus-forming murine leukemia viruses integrate in mouse $T, B$, and non-T/non-B cell lymphoma DNA. J Virol $57: 1037-1047$. 